\title{
The roles of oxytocin and CD38 in social or parental behaviors
}

\section{Olga Lopatina ${ }^{1}$, Alena Inzhutova ${ }^{1 \dagger}$, Alla B. Salmina ${ }^{1}$ and Haruhiro Higashida ${ }^{1,2 *}$}

${ }^{1}$ Department of Biochemistry, Medical, Pharmaceutical and Toxicological Chemistry, Krasnoyarsk State Medical University, Krasnoyarsk, Russia

${ }^{2}$ Research Center for Child Mental Development, Kanazawa University, Kanazawa, Japan

\section{Edited by:}

Richard Paul Ebstein, Yale University, USA

\section{Reviewed by:}

Yoichi Ueta, University of

Occupational and Environmental

Health, Japan

Kazuhiro Nakamura, Kyoto University,

Japan

\section{*Correspondence:}

Haruhiro Higashida, Research Center for Child Mental Development

Kanazawa University, Takara-Machi 13-1, Kanazawa 9208640, Japan.

e-mail: haruhiro@med.kanazawa-u. ac.jp

${ }^{\dagger}$ Deceased, August 29, 2012
The nine amino acid peptide oxytocin (OXT) has been directly associated with different types of behavioral reactions. The formation and maintenance of social relationships in youth and middle age are important components of human mental health. A deficit in healthy behavioral formation leads to social isolation and limitation of well-being. Mice are social animals and are therefore useful for investigating the neurobiological mechanisms of cognitive process control, including the development of social relationships and social skills. Studies in mice may broaden our understanding of the human condition. The multifunctional protein CD38/ADP-ribosyl cyclase is highly expressed in the brain, plays an important role in central OXT release, and regulates social memory. In this review article, we discuss the mechanisms of social behavior affected by the dysregulation of brain OXT function as a consequence of a lack of CD38. OXT bound to OXT receptors initiates autoregulatory positive feedback of OXT release in the hypothalamus and posterior pituitary. OXT biobehavioral positive feedback is usually implicated in female reproductive systems, but can also be observed in social behavior. Exogenous stimuli (OXT treatment in vitro, OXT intravenous or intraventricular administration, and nasal OXT delivery) initiate activation of OXT neurons via PKC-CD38/ADP-ribosyl cyclase cascades and result in the modulation of social behavior in humans and mice. Based on these findings, we reviewed the functions of OXT and its properties with respect to the development of therapies for human social behavior impairments in psychological diseases. In addition, preliminary studies of continuous nasal OXT administration on subjects with autism spectrum disorders are described.

Keywords: oxytocin, social behavior, social experience, parental care, CD38/ADP-ribosyl cyclase activity

\section{INTRODUCTION}

The nine amino acid peptide oxytocin (OXT) plays a dual role with peripheral and central effects in the regulation of many physiological and pathophysiological processes, including penile erection and ejaculation (Uckert et al., 2003; Vignozzi et al., 2004; Thackare et al., 2006), pregnancy and uterine contractions, milk ejection (Kendrick and Keverne, 1992; Keverne and Kendrick, 1992), osteoporosis (Elabd et al., 2008; Tamma et al., 2009), diabetes (Björkstrand et al., 1996; Gutkowska et al., 2009), cancer (Cassoni et al., 1996, 2002), the functioning of the cardiovascular system (Jankowski et al., 1998, 2012; Petersson and Uvnäs-Moberg, 2008), sexual activity (Pedersen and Boccia, 2002, 2006), pain modulation (Yang, 1994; Condés-Lara et al., 2005), stress, trust (Kosfeld et al., 2005; Hoge et al., 2012), anxiety (McCarthy et al., 1996; Heinrichs and Domes, 2008; Campbell, 2010), social interaction and bonding (mother-infant bonding or pair bonding) (Popik et al., 1992; Benelli et al., 1995; Insel, 1997, 2010; Kendrick, 2000; Young et al., 2001; Wang and Aragona, 2004; Young and Wang, 2004; Ebstein et al., 2009, 2011; Meyer-Lindenberg et al., 2011), and parental care (Modney and Hatton, 1994; Kendrick et al., 1997; Meaney, 2001; Fleming et al., 2002; Feldman and Eidelman, 2007; Feldman et al., 2011; Liu et al., 2012b). OXT is important for the processing or retention of direct and indirect social information
(Ferguson et al., 2001; Kavaliers et al., 2006; Modi and Young, 2012). The specific pattern of OXT secretion is related to the characteristics of behavioral reactions (Higashida et al., 2010, 2011, 2012a,b; Salmina et al., 2010).

With respect to OXT, we reported that CD38, a type II transmembrane protein, which controls leukemia malignancy in blood cells (Malavasi et al., 2008), is expressed in the brain and required for OXT secretion in mice (Jin et al., 2007). CD38 possesses ADPribosyl cyclase activity (Lee, 2012) that produces cyclic ADP-ribose (cADPR) from $\beta-\mathrm{NAD}^{+}$, which is an abundant substrate in the brain. cADPR is proposed as an intracellular second messenger, in that cADPR functions as a cofactor for $\mathrm{Ca}^{2+}$ mobilization through $\mathrm{Ca}^{2+}$-permeable channels $\left(\mathrm{Ca}^{2+}\right.$-induced $\mathrm{Ca}^{2+}$-release, CICR $)$ from ryanodine-sensitive $\mathrm{Ca}^{2+}$ pools, resulting in increases of cytosolic free $\mathrm{Ca}^{2+}$ concentrations $\left(\left[\mathrm{Ca}^{2+}\right]_{\mathrm{i}}\right)$. Therefore, it is postulated that some cellular events such as secretion or cell migration depend on the formation of CADPR.

In this review, we discuss recent research on the multiple functions of OXT and CD38 in social and parental behaviors. We propose cellular and systemic mechanisms for OXT and CD38 in social and parental behaviors, and we draw a schematic model of the signaling mechanism in a comprehensive manner. Finally, we focus on both single nucleotide polymorphisms (SNPs) of the human 
CD38 gene in relation to autism spectrum disorders (ASDs) and repetitive treatment of ASD patients with nasal administration of OXT.

\section{OXYTOCIN AND SOCIAL RELATIONSHIPS IN HUMANS}

Oxytocin is involved in different types of mammalian social behavior from rodents to humans in both sexes (Striepens et al., 2011). Social memory, as part of social behavior, is based on the ability to recognize conspecific forms (kin, mates, offspring, allies, and enemies) and is crucial for social life (DeBruine et al., 2008). In humans, faces provide important information about identity. OXT improves an individual's ability to produce normative ratings of others' emotions based on pictures of the eye regions of healthy adults (Domes et al., 2007). The blood OXT level is correlated with feelings of attachment (Tops et al., 2007; Campbell, 2008; Marazziti et al., 2009; Strathearn et al., 2009). OXT levels in the brain are increased in individuals with higher constructive approaches (Dai et al., 2012) compared to those with attachment avoidance (De Dreu, 2012). OXT may play an important health-promoting role in positive couple interactions (Ditzen et al., 2009).

The physiological functions of OXT in the regulation of mental health are confirmed by numerous studies of neuropsychiatric disorders. Individuals with obsessive compulsive disorder (OCD), ASDs, eating disorders, addiction, schizophrenia, and posttraumatic stress disorder (PTSD) show dysregulation of OXT levels (Leckman et al., 1994; Frasch et al., 1995; Marazziti and Cassano, 2003; Marroni et al., 2007; Meinlschmidt and Heim, 2008; Ishak et al., 2011). Trauma (Pierrehumbert et al., 2010) and PTSD (Marazziti and Cassano, 2003), as well as depression in women (Cyranowski et al., 2008), are associated with high pulsatile OXT levels, and very low OXT levels are associated with schizophrenia and ASD (Goldman et al., 2008; Kéri et al., 2009; Yamasue et al., 2009; Higashida et al., 2012b; Modi and Young, 2012).

The formation and maintenance of social relationships in youth and middle age are essential components of human mental health. Gaining an understanding of the neural, humoral, and genetic factors that regulate social behavior is crucial for human wellbeing (Kendrick, 2006). A deficit in healthy behavioral formation (ASD, schizophrenia, or social phobia) leads to social isolation. Thus, researchers need to understand the molecular mechanisms that sustain the establishment and modulation of relationships between individuals, especially in the context of treatment and drug therapy for patients. At present, little is known about the molecular mechanisms of OXT secretion in the context of social behavior in humans (Meyer-Lindenberg et al., 2011). Therefore, adequate animal models of OXT-mediated behavioral reactions are urgently required. Mice are social animals and are useful as models for investigating the neurobiological mechanisms of cognitive process control, which lead to the development of social relationships and skills. Studies in these animals may broaden our understanding of the human condition (Baker, 2011). A number of studies on the neurobiological bases of social behavior with mouse models have been performed; these studies were enriched with genetic technology in the form of gene "knockout" model mice.

\section{OXYTOCIN, SOCIAL MEMORY, AND CD38 IN RODENTS}

Male mice deficient in the gene encoding OXT (oxytocin knockout mice, $O x t^{-1-}$ ) displayed deficits in social recognition (Ferguson et al., 2000; Modi and Young, 2012) that could be reversed by intracerebroventricular infusion of OXT, and an infusion of an OXT antagonist inhibited social recognition in wild-type mice (Ferguson et al., 2001). This deficit was specific for social recognition: $O x t^{-1-}$ mice showed no impairments in other forms of learning or olfactory sensitivity and discrimination (Ferguson et al., 2000). Similar impairments in social recognition occurred in female $O x t^{-/-}$mice (Choleris et al., 2003). Oxt $t^{-/-}$mice showed increased anxiety and stress responses to psychogenic and certain physiological stimuli (Mantella et al., 2003; Amico et al., 2004). OXT receptor (OXTR) knockout mice $\left(\mathrm{Oxtr}^{-/-}\right)$emitted fewer ultrasonic vocalizations (USV), had higher levels of aggression, and showed social memory impairment (the latter of which could be abolished by OXT administration) compared to wild-type littermates (Takayanagi et al., 2005; Crawley et al., 2007; Macbeth et al., 2009; Sala et al., 2011).

However, social behavioral deficits could be caused not only by the lack of OXT and OXTR genes, but also by disturbance of the molecular mechanism involved in the cascade of OXT release. Deletion of the $C d 38$ gene in mice leads to deficits in social behavior due to abnormal central OXT secretion (Jin et al., 2007; Liu et al., 2008). CD38/ADP-ribosyl cyclase is a trifunctional enzyme, which is involved in the catalysis of cADPR from $\mathrm{NAD}^{+}$. This enzyme regulates intracellular calcium levels and is also responsible for hydrolysis of this molecule, as well as the total $\mathrm{NAD}^{+}$-glycohydrolase activity (Howard et al., 1993; Lee and Aarhus, 1995; Magni et al., 2004; Salmina et al., 2010; Lee, 2012). CD38 is expressed in murine (Ceni et al., 2003; Jin et al., 2007) and human brains (Mizuguchi et al., 1995; Munesue et al., 2010) and accounts for the majority of ADP-ribosyl cyclase activity in vitro (Malavasi et al., 2008; Lee, 2012). Cyclase activity corresponding to CD38 was detected in the brain during early embryonic mouse development, and the postnatal activity was enhanced until adult stages (Ceni et al., 2003, 2006).

\section{OXYTOCIN AND CYCLIC ADP-RIBOSE}

Oxytocin is mainly synthesized in the paraventricular hypothalamic nucleus (PVN) and supraoptic nucleus (SON), stored in Herring bodies and released into systemic circulation from the posterior pituitary (Oliver and Schäfer, 1895; Richard et al., 1991; Figure 1). ADP-ribosyl cyclase activity was demonstrated in the hypothalamus and posterior pituitary of the mouse brain; the activity in the hypothalamus was dominant (Jin et al., 2007). Cd38 gene knockout mice $\left(\mathrm{Cd} 38^{-/-}\right)$show impairment of glucoseinduced increases in $\mathrm{CADPR}, \mathrm{Ca}^{2+}$ concentration, and insulin secretion in pancreatic $\beta$-cells and the absence of $\mathrm{Ca}^{2+}$ oscillations in T cells (Takasawa et al., 1998; Kim et al., 2008). The lack of CD38 results in decreased ADP-ribosyl cyclase activity, lower levels of cADPR formation, and dysfunction of CICR; these deficiencies lead to alterations in OXT secretion in the hypothalamus and pituitary (Jin et al., 2007; Lopatina et al., 2010). This CD38-dependent secretion was specific to OXT but not to other transmitters, such as dopamine in the striatum or vasopressin in the hypothalamus (Jin et al., 2007). Other types of voltage-dependent $\mathrm{Ca}^{2+}$ channels 


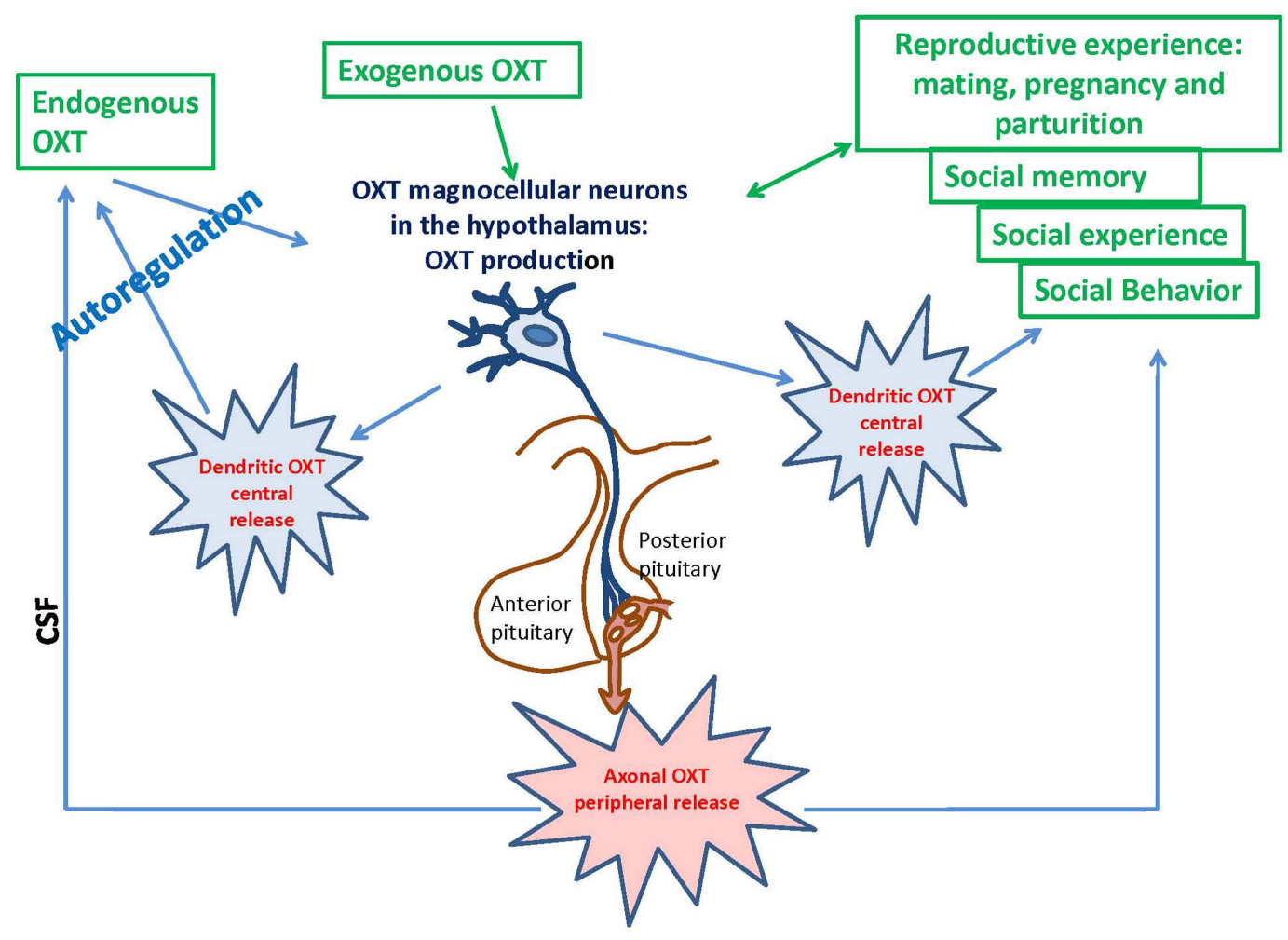

FIGURE 1 | Deletion of the Cd38 gene affects ADP-ribosyl cyclase activity, oxytocin release, and social behavior in male mice throughout their lifespans: significance of weaning.

are also involved in oxytocinergic neurons (Tobin et al., 2011). Recently, we showed that OXT release is also sensitive to hyperthermia and $\mathrm{Ca}^{2+}$ influx via TRPM2 channels (Amina et al., 2010; Liu et al., 2012a).

\section{SIGNAL TRANSDUCTION AND CD38 IN RODENTS}

The reproductive experience, rodent pup stimulation (sucking and olfactory signals), neurotransmitters, and hormones responsible for establishing parental behavior can activate many receptor complexes. For example, social (paternal) experience coincides with the efficiency of OXTR binding (Parker et al., 2001; De Jong et al., 2009). Receptor stimulation leads to the elevation of neuronal calcium levels and activation of the protein kinase C (PKC; Fleming et al., 1999). OXT is released from the axons of hypothalamic neurons, interacts with OXTR, and stimulates production of inositol 1,4,5-trisphosphate (IP3) and diacylglycerol (DAG) through the actions of phospholipase C (PLC; Gimpl and Fahrenholz, 2001) and PKC (Figure 2). Thus, this $\mathrm{PLC}$ - and $\mathrm{IP}_{3}$-dependent $\mathrm{Ca}^{2+}$ signaling pathway may function in the mechanism of autoregulation of OXT release (Lambert et al., 1994), i.e., the direct action of OXT on OXT neurons mediated by OXTR. The positive feedback mechanism of OXT release plays a critical and physiological role in causing uterine contractions during labor and milk release during breastfeeding in rodents (Moos et al., 1984; Neumann et al., 1994, 1996).
In rats, the binding of OXT to OXTR causes biochemical and transcriptional changes that account for the immediate and long-term neuromodulatory effects of OXT (Erwin et al., 2011). Blocking OXTR reduces lactation-related behaviors (Pedersen and Boccia, 2003; Bosch and Neumann, 2008), increases anxietyrelated behaviors (Bosch and Neumann, 2008), and affects maternal offensive and defensive behaviors (Bosch et al., 2005; Febo et al., 2009). An in vitro study showed that OXT stimulates its own release from tissue blocks containing both SON and PVN (Moos et al., 1984). Many neuronal OXT responses are important for particular behavioral or physiological functions. Elucidating the signal transduction mechanisms mediating the effects of released OXT on cellular characteristics may reveal the principles of critical autoregulation for the functioning of the mammalian brain (Dayanithi et al., 2000; Landgraf and Neumann, 2004).

We were interested in the mechanism by which CD38/ADPribosyl cyclase is activated after OXTR stimulation in the hypothalamus (which leads to secretion of OXT) and how this mechanism is related to social recognition or social behavior in the $C d 38^{-/-}$ strain (Jin et al., 2007; Liu et al., 2008).

\section{OXYTOCIN AND CYTOSOLIC CALCIUM IN THE HYPOTHALAMUS}

Our in vitro experiments with the hypothalamus and posterior pituitary of adult male mice (Lopatina et al., 2010) indicated 


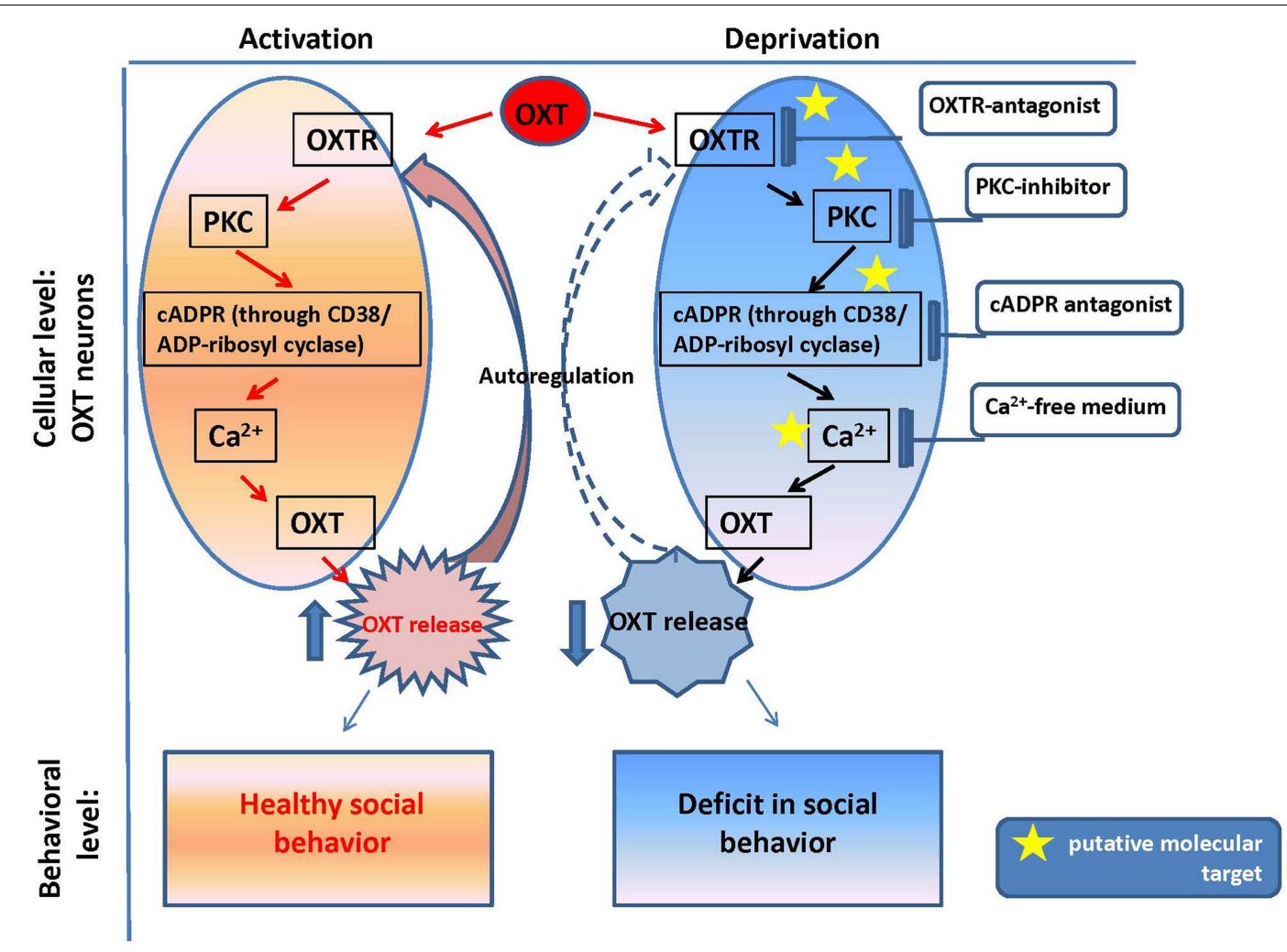

FIGURE 2 | Oxytocin positive feedback control and oxytocin signaling in psychophysiological development.

the involvement of the CD38/Cyclic ADP-ribosyl systems in the autoregulation of OXT secretion. The maximum increase in ADP-ribosyl cyclase activity (in crude membranes prepared from the hypothalamus and posterior pituitary of adult male mice in response to $10 \mathrm{nM}$ OXT) was 1.6 -fold higher than the pre-exposure levels in the hypothalamus, while the activity was increased by 2.8 -fold in response to 10 pM OXT in the pituitary (Lopatina et al., 2010). Simultaneous application of vasotocin, an OXTR antagonist, significantly inhibited the OXT-induced increase in ADP-ribosyl cyclase activity. Intracellular cADPR levels increased during incubation with OXT for $5 \mathrm{~min}$ in a dosedependent manner. ADP-ribosyl cyclase was also activated by kinases via the OXT signaling pathway, which was sensitive to $5 \mathrm{nM}$ staurosporine (a non-selective inhibitor of protein kinases) and $100 \mathrm{nM}$ calphostin C (a specific PKC inhibitor) in both tissues. The results confirmed that OXT-mediated OXT release in male mice, and this process was dependent on both CADPR and $\mathrm{Ca}^{2+}$, which are mediated by PKC (Figure 2). The OXTinduced reactions in the signal cascade were sensitive to PKC inhibitors.

The OXT release was observed in tissue blocks acutely isolated from the mouse hypothalamus, in which the nerve terminals of the oxytocinergic neurons were not present (Jin et al., 2007). Thus, OXT secretion observed in such conditions is caused by cell soma, recurrent axons, and axonal swellings. This somato-axonal OXT release was closely correlated with intracellular $\mathrm{Ca}^{2+}$ dynamics. More importantly, the endoplasmic reticulum $\mathrm{Ca}^{2+}$ stores play a major role in $\mathrm{Ca}^{2+}$ homeostasis in identified OXT neurons because no release was detected in depletion of stored $\mathrm{Ca}^{2+}$ under the $\mathrm{Ca}^{2+}$-free condition (Higashida et al., 2010; Salmina et al., 2010). Because a $\mathrm{Ca}^{2+}$-free medium is assumed to block synaptic transmission, the above results suggest a direct action of OXT on OXT neurons (Figure 2).

The OXT-induced $\mathrm{Ca}^{2+}$ elevation is due to cADPR-induced $\mathrm{Ca}^{2+}$ release from intracellular stores mediated by ryanodine receptors in a PKC-dependent manner, followed by $\mathrm{Ca}^{2+}$ mobilization due to activation of the $\mathrm{IP}_{3}$ receptors, which was not sensitive to $\mathrm{PKC}$ in the mouse hypothalamus (Lopatina et al., 2011). PKC is involved in the stimulation of ADP-ribosyl cyclase activity-mediated $\left[\mathrm{Ca}^{2+}\right]_{\mathrm{i}}$ increase, and facilitation of OXT release. Autoregulation is usually attributed to the female reproductive system. Fleming et al. (1999) previously demonstrated that maternal experience initially stimulates enhanced PKC synthesis and activation of c-fos gene expression in the maternal system [e.g., medial preoptic area (MPOA)]. Reproduction-related stimuli cause positive feedback release of OXT within the brains of lactating rats (Brunton and Russell, 2010). Our data on parental behaviors and social recognition, and the findings of our in vitro study indicate that social (reproductive) experience activates OXT neurons, increases hypothalamic CD38/ADP ribosyl cyclase activity, stimulates OXT release from the axons and potentially from the dendrites, and induces OXT autoregulation (Lopatina et al., 2011; Higashida et al., 2012b). These observations together indicate that positive feedback of PKC- and cADPR-dependent OXT release 


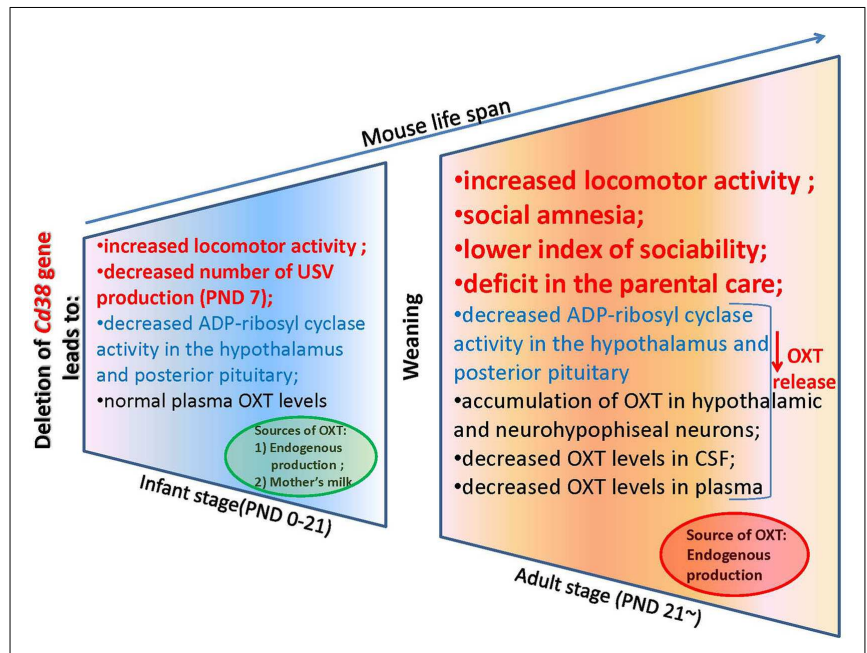

FIGURE 3 | An oxytocin release feedback loop and potential molecular targets for pharmacotherapy of alterations in social behavior.

in the hypothalamus and pituitary is important for correct and efficient social conduct in relation to social stimulation (Figure 2). OXT initiates activation of OXTR + neurons through the PKCCD38/ADP-ribosyl cyclase cascade, thus leading to modulation of social behavior in mice. Such a mechanism may also be an important component of human social behavior adjustment to external stimuli (Figure 1).

\section{OXYTOCIN LEVELS IN CD38 KNOCKOUT MICE}

To explain this tendency, we measured the plasma OXT levels in the CD38 knockout mice (Liu et al., 2008). Interestingly, the plasma OXT levels were comparable in both genotypes during the first 3 weeks after birth until weaning; this was followed by a significant reduction of plasma OXT levels in $C d 38^{-/-}$mice after the weaning period ( $>3$ weeks). In $C d 38^{-/-}$mice, ADPribosyl cyclase activity was markedly lower in the hypothalamus and pituitary from the first postnatal day and was consistently lower thereafter until the adult stage in comparison with $C d 38^{+/+}$ mice (Figure 3). The reduced severity of behavioral abnormalities in $C d 38^{-/-}$pups was due to partial compensation by high levels of plasma OXT. Therefore, the weaning time in $\mathrm{Cd} 38^{-/-}$ mice seems to be a critical period for distinguishing different plasma OXT levels as the mice transition from the infant to the adult stage. We speculated that $C d 38^{-/-}$pups take in OXT from the dams' milk, which helps them recover from their own OXT secretion deficits (Higashida et al., 2010). We found that OXT was abundant in the mammary gland tissue and milk of lactating dams of both genotypes. Milk OXT may be transported into the bloodstream.

This supports the suggestion that maternal behavior is directed at infant care not only by sustaining protection and nurturing, but also by permitting a longer period of brain development after birth (Pedersen, 1999; Feldman and Eidelman, 2007). As expected, human studies showed that plasma and salivary OXT levels in mothers are associated with parent and child's social engagement, affect synchrony, and positive communicative sequences between the parent and child (Feldman and Eidelman, 2003; Feldman et al., 2004, 2010, 2011).

\section{CD38 AND OXYTOCIN SECRETION IN MICE}

The plasma and cerebrospinal fluid (CSF) OXT levels were significantly lower in $\mathrm{Cd} 38^{-/-}$mice than $\mathrm{Cd} 38^{+/+}$mice, but the OXT levels were elevated in the hypothalamus and pituitary, in comparison with wild-type mice. These data clearly demonstrate normal OXT production and packaging into vesicles in the hypothalamic neurons and posterior pituitary nerve endings in $C d 38^{-/-}$ mice, but altered OXT release into the brain and bloodstream (Jin et al., 2007; Higashida et al., 2012b). Indeed, the behavioral phenotypes of $C d 38^{-/-}$mice could be normalized by even a single subcutaneous OXT injection and also by infusion of a virus carrying the human $C D 38$ gene into the third ventricle of knockout mice; this result indicates the requirement of CD38-dependent OXT secretion for development of special types of social behavior (Jin et al., 2007; Higashida et al., 2010; Salmina et al., 2010; Figure 2).

We also identified significant abnormalities in maternal nurturing behavior in $C d 38^{-/-}$postpartum mice under stressful conditions, such as pup-dam separation (Jin et al., 2007). Female $C d 38^{-/}$mice displayed disrupted maternal behavior in the retrieval test. Wild-type dams retrieved all five test pups very quickly and directly to the nest arena, whereas $C d 38^{-/-}$dams took a significantly longer time to begin retrieval, moved around continuously, and often dropped the pups during retrieval (suggesting memory loss of the way to the nest), resulting in the pups becoming scattered in different places. However, after reunion, $C d 38^{-/-}$dams fed the pups sufficiently for them to grow to the same weight as the controls (Jin et al., 2007; Lopatina et al., 2011; Higashida et al., 2012a).

\section{SOCIAL BEHAVIORS IN CD38 KNOCKOUT MICE}

We now describe the social behavior in $C d 38^{-/-}$mice in relation to the brain and plasma OXT levels in the context of CD38/ADP-ribosyl cyclase activity-dependent mechanisms of OXT secretion. We especially focus on infant male behavior, social skills in adult males, and parental (maternal and paternal) behavior in $C d 38^{-/-}$mice (Figure 3 ). In addition, we summarize the ADPribosyl cyclase/cADPR-controlled $\left[\mathrm{Ca}^{2+}\right]_{\mathrm{i}}$ signaling involved in the autoregulatory positive feedback of OXT release in the hypothalamus and posterior pituitary, resulting in special types of social behavior.

$C d 38^{-/-}$mice grew well and showed the same weight gain as wild-type $\left(C d 38^{+/+}\right)$mice (Jin et al., 2007; Liu et al., 2008). Alterations in locomotor activity and exploration are important consequences of the paradigms used to study specific processes, such as learning, memory, and anxiety. The individual and group locomotor activities (induced by separation stress from the dam) were significantly higher in 7-day-old $C d 38^{-/-}$mouse pups than in $C d 38^{+/+}$controls (Liu et al., 2008; Figure 1). Locomotor abnormalities are associated with human psychiatric diseases (Gil-Bea et al., 2007; Touma et al., 2008; Silverman et al., 2011; Won et al., 2011); these diseases are difficult to model in rodents because of the variability of symptoms and the absence of verbal communication (Onaivi et al., 2011). Nevertheless, a number of relevant 
behavioral and social changes have been documented in transgenic mouse models of neurodevelopmental disorders (Branchi et al., 2001; Brooks et al., 2005; Crawley, 2007; Moy et al., 2007, 2008; Wöhr et al., 2011).

\section{OXYTOCIN AND REPRODUCTION EXPERIENCE IN MICE}

The search for the mechanisms that control the transmission of the OXT bio-behavioral feedback loop indicated that social experience may modulate brain plasticity (Insel and Young, 2001), and OXT production and functions are based on behavioral and neural changing mechanisms as well as on genetic mechanisms (Modney and Hatton, 1994; Fleming et al., 1999). One of the constituent parts of social experience is the reproductive experience (including mating, pregnancy, and parturition; Figure 1). The reproductive experience is also an important factor for the expression of maternal behavior, and additional parenting experience is necessary to confer induction of parental maternal behavior (Okabe et al., 2010; Liu et al., 2012b; Nagasawa et al., 2012). OXT-induced long-term potentiation is affected by mothering (Tomizawa et al., 2003). The initial (primiparity and mothering) reproductive experience results in behavioral, hormonal, and neural changes in the mother that markedly alter subsequent reproductive experiences (Pawluski et al., 2006). Therefore, we examined the positive effect on reproductive experience in parental behavior by multiparous $C d 38^{-/-}$dams. They retrieved pups faster than primiparous $C d 38^{-/-}$mice, whereas there were no significant differences between primiparous and multiparous $\mathrm{Cd} 38^{+/+}$dams in the retrieval test (Lopatina et al., 2011). The plasma OXT levels were significantly increased in multiparous dams compared to primiparous dams of both genotypes. In addition, OXT levels in the hypothalamus and pituitary were lower in $\mathrm{Cd} 38^{-/-}$dams than wild-type controls because OXT is released into the brain and blood in experienced mice. ADP-ribosyl cyclase activity in the hypothalamus, but not in the pituitary, was slightly increased in $C d 38^{+/+}$dams. Thus, mouse maternal OXT is related to the reproductive experience and positive maternal behavior (Figure 3). Whether this mechanism is significant for human maternal behavior remains to be elucidated.

Associations between peripheral OXT and parenting were also found in fathers, suggesting that OXT neuronal pathways may be activated through the provision of paternal care (Feldman et al., 2010, 2011; Liu et al., 2012b). The experiments on the paternal behavior in mice showed that only $40 \%$ of firsttime $\mathrm{Cd} 38^{+/+}$sires displayed paternal care in the retrieval test (Lopatina et al., 2011). Both first- and second-time Cd38-/sires showed only $10 \%$ retrieval behavior. The time required to retrieve five pups to the nest was shorter for second-time $\mathrm{Cd} 38^{+/+}$sires, and this time was associated with increased hypothalamic ADP-ribosyl cyclase activity. Induction of ADP-ribosyl cyclase activity leads to stimulation of OXT release and elevated plasma OXT levels as observed in dams. Therefore, the reproductive experience improves parental behavior, especially in $\mathrm{Cd} 38^{-/-}$ dams, suggesting the involvement of OXT systems in reproductive experience-mediated remodeling of the neuroendocrine system.

\section{SOCIAL INFORMATION TRANSMISSION IN MICE}

In mammals, transmission of social information is critical for the establishment of all aspects of social behavior, sociability, and sociality: humans use language, while mice have USV, which may be a measure of social communication in mice (Crawley, 2004). Studies have used pup vocalizations as a sensitive behavioral endpoint (Iijima and Chaki, 2005; Scattoni et al., 2008). One standard test for vocalization in mice is the ultrasonic distress call of pups separated from the dam or removed from the nest (Winslow et al., 2000; Branchi et al., 2001; Shu et al., 2005). Mouse pups emit isolation-induced USVs that have the characteristics of songs, which consist of several different syllable types and the temporal sequencing includes the utterance of repeated phrases. The isolation-induced USVs are emitted by both $\mathrm{Cd} 38^{+/+}$and $C d 38^{-/}$pups and have the same frequency $(\sim 70 \mathrm{kHz})$ and duration $(\sim 60 \mathrm{~ms})$. The number of USVs was significantly (1.6-fold) lower in $\mathrm{Cd} 38^{-/-}$pups than in $\mathrm{Cd} 38^{+/+}$pups. Reduced USVs in mice are a useful parameter relevant to the second diagnostic symptom of autism, impaired communication (Klin et al., 2007; Scattoni et al., 2008). Our findings in $C d 38^{-/-}$mice are very similar to the communicative alterations found in $\mathrm{Oxt}^{-/-}$and $\mathrm{Oxtr}^{-/-}$ mice (Nishimori et al., 1996; Ferguson et al., 2000; Winslow et al., 2000; Takayanagi et al., 2005; Crawley et al., 2007). However, $C d 38^{-1-}$ mice have smoother patterns of behavioral expression than mice lacking the Oxt or Oxtr genes.

\section{SOCIAL RESPONSES AND CD38 IN MICE}

The formation and maintenance of social relationships are complex processes that involve several stages of information processing in the human brain. Investigations of social behavior in animals generally focus on a single level of processing at a given time point (Lim and Young, 2006). However, social recognition is necessary for the establishment of social bonds between individuals. Understanding the neurobiological bases of social recognition and the use of social information transmission in mice can allow translation of the proximal mechanisms of sociality to humans (Tang-Martinez, 2003; Choleris et al., 2004). Individual recognition can be operationally defined as unique modifications; an animal behaves toward another animal by relying on past experiences that are specific to individuals (Gheusi et al., 1994). The $C d 38$ gene deficit is associated with social amnesia in social recognition tasks (Ferguson et al., 2000; Choleris et al., 2004), which detect the natural propensity of mice to investigate an intruder mouse that is presented repeatedly. In normal behavior, the social response of the resident mouse declines to very low levels (habituation). $C d 38^{-/-}$males did not habituate to intruder females after repeated encounters and displayed sustained high levels of investigation at all encounters with the same female, whereas $\mathrm{Cd} 38^{+/+}$ male mice exhibited a significant decline in the investigation time and positive social memory (Jin et al., 2007; Higashida et al., 2012b). This amnesia resembles the memory deficit observed in $\mathrm{Oxt}^{-1-}$ and $\mathrm{Oxtr}^{-1-}$ mice (Ferguson et al., 2000; Takayanagi et al., 2005). A single subcutaneous injection of OXT rescued the social memory deficits of $C d 38^{-/-}$mice because OXT may enter the brain, probably due to the blood-brain barrier (BBB) permeability for OXT or some other pathways (McEwen, 2004; 
Bartz and Hollander, 2006; Hollander et al., 2007; Jin et al., 2007; Churchland and Winkielman, 2012). Social and individual recognition facilitates social interactions in group life and is considered to be one of the key evolutionary underpinnings of sociality (Altizer et al., 2003; Kavaliers et al., 2005; Choleris et al., 2009; Figure 1).

\section{OXYTOCIN, CD38, AND AUTISM SPECTRUM DISORDERS}

A recent series of studies in humans showed that nasal infusion of OXT increases trust (Kosfeld et al., 2005; Baumgartner et al., 2008), mindreading (Domes et al., 2007), and generosity (Zak et al., 2007), indicating an important role of OXT in human social behavior (MacDonald and MacDonald, 2010; MacDonald et al., 2011). Furthermore, OXT reduces repetitive behavior in adults with autism and Asperger's disorder (Hollander et al., 2003).

Studies have reported associations between parental and infant OXT levels with the degree of contingent parenting (Feldman and Eidelman, 2003, 2007; Feldman et al., 2004). Maternal postpartum behavior has long-term effects on infants' cognitive, neurobehavioral, and social-emotional growth. Mother-infant touch and contact stimulate OXT release (Matthiesen et al., 2001). OXT and CD38 are related to higher levels of parental care and longer episodes of gaze synchrony with infants (Feldman et al., 2012). Maternal OXT is related to sensitive and emotional behavior (Gordon et al., 2010; Strathearn et al., 2012) and an increased blood oxygenation-level dependent (BOLD) functional magnetic resonance imaging (fMRI) response to infant stimuli in brain areas rich with OXTR (Strathearn et al., 2009). Paternal OXT is correlated with tactile stimulation and exploratory play with tasks oriented toward their infants (Gordon et al., 2010; Weisman et al., 2012). Mothers and fathers who provided high levels of tactile contact to their infants showed an increase in salivary OXT following parent-infant interactions, but no increase was observed among parents who provided low tactile contact (Feldman et al., 2010). In a similar way, high and low licking-and-grooming patterns of rat and mouse dams have differential impacts on OXT expression. In humans, there is a general consensus that both prenatal and postpartum OXT enhance the formation of close bonds with the infant and reduce maternal stress reactivity (Nelson and Panksepp, 1998; Neumann, 2008; Campbell, 2010). OXT inhalation increased the fathers' responsiveness to their toddlers, particularly in the father-specific pattern (Naber et al., 2010; Weisman et al., 2012). Variations in the OXTR gene were related to the degree of maternal sensitivity to OXT (Bakermans-Kranenburg and van Ijzendoorn, 2008; Feldman et al., 2010). The importance of SNPs of OXTR has been discussed in relation to ASDs (Ebstein et al., 2010; Insel, 2010). OXT activates neural circuitries related to empathy in women exposed to the crying of an infant (Riem et al., 2011). The central and peripheral OXT measurements revealed meaningful differences in parenting behavior in humans, similar to the roles in other mammals. The matching of rodent and human studies is valuable for translational research in this field of medicine.

CD38 mRNA is expressed in many different regions in the human brain, including the hypothalamus, where CD38 colocalizes with oxytocinergic neuronal structures (Munesue et al., 2010). OXT plasma levels are lower in ASD patients than in individuals without this disorder (Modahl et al., 1998; Munesue et al., 2010). A mutation in the CD38 gene is associated with ASD and lower OXT levels (Munesue et al., 2010). CD38 expression in human lymphoblastoid cell (LBC) lines obtained from subjects with ASD and their "unaffected" parents demonstrated significant reduction of expression in affected subjects (Lerer et al., 2009, 2010; Ebstein et al., 2012). The therapeutic potency of all-trans retinoic acid increases CD38 expression (Ebstein et al., 2011). There are significant correlations between CD38 expression, VABS score and IQ in humans (Riebold et al., 2011). Similar allele frequencies for the genotyped SNPs in men and women and similar correlations between plasma OXT, CD38, or human OXTR SNP variants and parenting behavior have been observed between human mothers and fathers (Feldman et al., 2012). However, the predictive effect of CD38 expression was not confined to the trust-related condition. Therefore, they suggested a role of CD38 in basal OXT release rather than OXT release associated with emotional events in humans (Kiss et al., 2011); although, no direct evidence was presented.

\section{SUBJECTS WITH AUTISM SPECTRUM DISORDERS TREATED BY OXYTOCIN}

Indeed, positive feedback of OXT-induced OXT release was recently observed in human males. OXT was shown to enhance visual scanning of faces, particularly the eye region, as compared to a placebo. Plasma or salivary OXT levels are significantly increased after intranasal OXT administration (Andari et al., 2010; Huffmeijer et al., 2012). Nasal OXT treatment has minor effects in improving cognitive empathy and socially motivated learning (Hurlemann et al., 2010). However, nasal OXT administration facilitates trust and reduces social anxiety in conditions of social phobia and borderline personality disorder (Kosfeld et al., 2005; Bartz and Hollander, 2006; Heinrichs and Domes, 2008; Guastella et al., 2009; Guastella and MacLeod, 2012). OXT improves social cognition in autistic individuals (Domes et al., 2007; Bartz and Hollander, 2008; Guastella et al., 2010). Nasal OXT spray can modify social signals and the social feedback process in high-functioning autistic patients (Andari et al., 2010; Bartz et al., 2010; Hirosawa et al., 2012). Thus, several OXT-controlled processes have been implicated in different types of mammalian social behavior. In addition, there are three reports that indicate symptomatic improvement of male and female ASD patients with long-term OT treatment (Munesue et al., 2010; Higashida et al., 2012b; Kosaka et al., 2012).

\section{CONCLUSION}

In summary, recent data suggest novel mechanisms underlying social behavior and confirm new molecular targets for pharmacological corrections of behavioral changes associated with neurodevelopmental disorders. The plasma OXT level is a reliable marker reflecting central oxytocinergic functions in humans. Rodent models are useful in this research field to investigate the molecular mechanisms underlying the disturbance of central and peripheral OXT regulation and to develop new perspectives in the therapy of human diseases characterized by social behavior deficits. 


\section{REFERENCES}

Altizer, S., Nunn, C. L., Thrall, P. H., Gittleman, J. L., Antonovics, J., Cunningham, A. A., et al. (2003). Social organization and parasite risk in mammals: integrating theory and empirical studies. Annu. Rev. Ecol. Syst. 34, 517-547.

Amico, J. A., Mantella, R. C., Vollmer, R. R., and Li, X. (2004). Anxiety and stress responses in female oxytocin deficient mice. J. Neuroendocrinol. 16, 319-324.

Amina, S., Hashii, M., Ma, W. J., Yokoyama, S., Lopatina, O., Liu, H. X., et al. (2010). Intracellular calcium elevation induced by extracellular application of cyclic-ADPribose or oxytocin is temperaturesensitive in rodent NG108-15 neuronal cells with or without exogenous expression of human oxytocin receptors. J. Neuroendocrinol. 22, 460-466.

Andari, E., Duhamel, J. R., Zalla, T., Herbrecht, E., Leboyer, M., and Sirigu, A. (2010). Promoting social behavior with oxytocin in highfunctioning autism spectrum disorders. Proc. Natl. Acad. Sci. U.S.A. 107, 4389-4394.

Baker, M. (2011). Animal models: inside the minds of mice and men. Nature 475, 123-128.

Bakermans-Kranenburg, M. J., and van Ijzendoorn, M. H. (2008). Oxytocin receptor (OXTR) and serotonin transporter (5-HTT) genes associated with observed parenting. Soc. Cogn. Affect. Neurosci. 3, 128-134.

Bartz, J. A., and Hollander, E. (2006). The neuroscience of affiliation: forging links between basic and clinical research on neuropeptides and social behavior. Horm. Behav. 50, 518-528.

Bartz, J. A., and Hollander, E. (2008). Oxytocin and experimental therapeutics in autism spectrum disorders. Prog. Brain Res. 170, 451-462.

Bartz, J. A., Zaki, J., Ochsner, K. N., Bolger, N., Kolevzon, A., Ludwig, N., et al. (2010). Effects of oxytocin on recollections of maternal care and closeness. Proc. Natl. Acad. Sci. U.S.A. 107, 21371-21375.

Baumgartner, T., Heinrichs, M., Vonlanthen, A., Fischbacher, U., and Fehr, E. (2008). Oxytocin shapes the neural circuitry of trust and trust adaptation in humans. Neuron 58, 639-650.

Benelli, A., Bertolini, A., Poggioli, R., Menozzi, B., Basaglia, R., and Arletti, R. (1995). Polymodal dose-response curve for oxytocin in the social recognition test. Neuropeptides 28, 251-255.
Björkstrand, E., Eriksson, M., and Uvnäs-Moberg, K. (1996). Evidence of a peripheral and a central effect of oxytocin on pancreatic hormone release in rats. Neuroendocrinology 63, 377-383.

Bosch, O. J., Meddle, S. L., Beiderbeck, D. I., Douglas, A. J., and Neumann, I. D. (2005). Brain oxytocin correlates with maternal aggression: link to anxiety. J. Neurosci. 25, 6807-6815.

Bosch, O. J., and Neumann, I. D. (2008). Brain vasopressin is an important regulator of maternal behavior independent of dams' trait anxiety. Proc. Natl. Acad. Sci. U.S.A. 105, 17139-17144.

Branchi, I., Santucci, D., and Alleva, E. (2001). Ultrasonic vocalisation emitted by infant rodents: a tool for assessment of neurobehavioural development. Behav. Brain Res. 125, 49-56.

Brooks, S. P., Pask, T., Jones, L., and Dunnett, S. B. (2005). Behavioural profiles of inbred mouse strains used as transgenic backgrounds. II: cognitive tests. Genes Brain Behav. 4, 307-317.

Brunton, P. J., and Russell, J. A. (2010). Endocrine induced changes in brain function during pregnancy. Brain Res. 1364, 198-215.

Campbell, A. (2008). Attachment, aggression and affiliation: the role of oxytocin in female social behavior. Biol. Psychol. 77, 1-10.

Campbell, A. (2010). Oxytocin and human social behavior. Pers. Soc. Psychol. Rev. 14, 281-295.

Cassoni, P., Sapino, A., Deaglio, S., Bussolati, B., Volante, M., Munaron, L., et al. (2002). Oxytocin is a growth factor for Kaposi's sarcoma cells: evidence of endocrineimmunological cross-talk. Cancer Res. 62, 2406-2413.

Cassoni, P., Sapino, A., Papotti, M., and Bussolati, G. (1996). Oxytocin and oxytocin-analogue F314 inhibit cell proliferation and tumor growth of rat and mouse mammary carcinomas. Int. J. Cancer 66, 817-820.

Ceni, C., Pochon, N., Brun, V., MullerSteffner, H., Andrieux, A., Grunwald, D., et al. (2003). CD38-dependent ADP-ribosyl cyclase activity in developing and adult mouse brain. Biochem. J. 370, 175-183.

Ceni, C., Pochon, N., Villaz, M., Muller-Steffner, H., Schuber, F., Baratier, J., et al. (2006). The CD38independent ADP-ribosyl cyclase from mouse brain synaptosomes: a comparative study of neonate and adult brain. Biochem. J. 395, 417-426.
Choleris, E., Clipperton-Allen, A. E. Phan, A., and Kavaliers, M. (2009). Neuroendocrinology of social information processing in rats and mice. Front. Neuroendocrinol. 30 442-459.

Choleris, E., Gustafsson, J.-A., Korach, K. S., Muglia, L. J., Pfaff, D. W., and Ogawa, S. (2003). An estrogen dependent micronet mediating social recognition. A study with oxytocin- and estrogenreceptor $\alpha$ - and $\beta$-knockout mice. Proc. Natl. Acad. Sci. U.S.A. 100, 6192-6197.

Choleris, E., Kavaliers, M., and Pfaff, D. W. (2004). Functional genomics of social recognition. J. Neuroendocrinol. 16, 383-389.

Churchland, P. S., and Winkielman, P. (2012). Modulating social behavior with oxytocin: how does it work? What does it mean? Horm. Behav. 61 , 392-399.

Condés-Lara, M., Maie, I. A., and Dickenson, A. H. (2005). Oxytocin actions on afferent evoked spinal cord neuronal activities in neuropathic but not in normal rats. Brain Res. 1045, 124-133.

Crawley, J. N. (2004). Designing mouse behavioral tasks relevant to autisticlike behaviors. Ment. Retard. Dev. Disabil. Res. Rev. 10, 248-258.

Crawley, J. N. (2007). Mouse behavioral assays relevant to the symptoms of autism. Brain Pathol. 17, 448-459.

Crawley, J. N., Chen, T., Puri, A., Washburn, R., Sullivan, T. L., Hill, J. M., et al. (2007). Social approach behaviors in oxytocin knockout mice: comparison of two independent lines tested in different laboratory environments. Neuropeptides 41, 145-163.

Cyranowski, J. M., Hofkens, T. L., Frank, E., Seltman, H., Cai, H. M., and Amico, J. A. (2008). Evidence of dysregulated peripheral oxytocin release among depressed women. Psychosom. Med. 70, 967-975.

Dai, L., Carter, C. S., Ying, J., Bellugi, U., Pournajafi-Nazarloo, H., and Korenberg, J. R. (2012). Oxytocin and vasopressin are dysregulated in Williams syndrome, a genetic disorder affecting social behavior. PLOS ONE 7:e38513. doi:10.1371/journal.pone.0038513

Dayanithi, G., Sabatier, N., and Widmer, H. (2000). Intracellular calcium signaling in magnocellular neurones of the rat supraoptic nucleus: understanding the autoregulatory mechanisms. Exp. Physiol. 85, 75S-84S.

De Dreu, C. K. W. (2012). Oxytocin modulates the link between adult attachment and cooperation through reduced betrayal aversion. Psychoneuroendocrinology 37, 871-880.

De Jong, T. R., Chauke, M., Harris, B. N., and Saltzman, W. (2009). From here to paternity: neural correlates of the onset of paternal behaviour in California mice (Peromyscus californicus). Horm. Behav. 56, 220-231.

DeBruine, L. M., Jones, B. C., Little, A. C., and Perrett, D. I. (2008). Perrett social perception of facial resemblance in humans. Arch. Sex. Behav. 37, 64-77.

Ditzen, B., Schaer, M., Gabriel, B., Bodenmann, G., Ehlert, U., and Heinrichs, M. (2009). Intranasal oxytocin increases positive communication and reduces cortisol levels during couple conflict. Biol. Psychiatry $65,728-731$.

Domes, G., Heinrichs, M., Michel, A., Berger, C., and Herpertz, S. C. (2007). Oxytocin improves "mindreading" in humans. Biol. Psychiatry 61, 731-733.

Ebstein, R. P., Israel, S., Chew, S. H., Zhong, S., and Knafo, A. (2010). Genetics of human social behavior. Neuron 65, 831-844.

Ebstein, R. P., Israel, S., Lerer, E., Uzefovsky, F., Shalev, I., Gritsenko, I., et al. (2009). Arginine vasopressin and oxytocin modulate human social behavior. Ann. N. Y. Acad. Sci. 1167, 87-102.

Ebstein, R. P., Knafo, A., Mankuta, D., Chew, S. H., and Lai, P. S. (2012). The contributions of oxytocin and vasopressin pathway genes to human behavior. Horm. Behav. 61, 359-379.

Ebstein, R. P., Mankuta, D., Yirmiya, N., and Malavasi, F. (2011). Are retinoids potential therapeutic agents in disorders of social cognition including autism? FEBS Lett. 585, 1529-1536.

Elabd, C., Basillais, A., Beaupied, H., Breuil, V., Wagner, N., Scheideler, M. et al. (2008). Oxytocin controls differentiation of human mesenchymal stem cells and reverses osteoporosis. Stem Cells 26, 2399-2407.

Erwin, H., den Burg, V., and Neumann, I. D. (2011). Bridging the gap between GPCR activation and behaviour: oxytocin and prolactin signalling in the hypothalamus. $J$. Mol. Neurosci. 43, 200-208.

Febo, M., Shieldsb, J., Ferrisa, C. F., and Kingb, J. A. (2009). Oxytocin modulates unconditioned fear response in lactating dams: an fMRI study. Brain Res. 1302, 183-193.

Feldman, R., and Eidelman, A. I. (2003). Direct and indirect effects of maternal milk on the neurobehavioral 
and cognitive development of premature infants. Dev. Psychobiol. 43, 109-119.

Feldman, R., and Eidelman, A. I. (2007). Maternal postpartum behavior and the emergence of infant-mother and infant-father synchrony in preterm and full-term infants: the role of neonatal vagal tone. Dev. Psychobiol. 49, 290-302.

Feldman, R., Eidelman, A. I., and Rotenberg, N. (2004). Parenting stress, infant emotion regulation, maternal sensitivity, and the cognitive development of triplets: a model for parent and child influences in a unique ecology. Child Dev. 75, 1774-1791.

Feldman, R., Gordon, I., Schneiderman, I., Weisman, O., and Zagoory-Sharon, O. (2010). Natural variations in maternal and paternal care are associated with systematic changes in oxytocin following parent-infant contact. Psychoneuroendocrinology 35, 1133-1141.

Feldman, R., Gordon, I., and ZagoorySharon, O. (2011). Maternal and paternal plasma, salivary, and urinary oxytocin and parent-infant synchrony: considering stress and affiliation components of human bonding. Dev. Sci. 14, 752-761.

Feldman, R., Zagoory-Sharon, O., Weisman, O., Schneiderman, I., Gordon, I., Maoz, R., et al. (2012). Sensitive parenting is associated with plasma oxytocin and polymorphisms in the OXTR and CD38 genes. Biol. Psychiatry $72,175-181$.

Ferguson, J. N., Aldag, J. M., Insel, T. R., and Young, L. J. (2001). Oxytocin in the medial amygdala is essential for social recognition in the mouse. $J$. Neurosci. 21, 8278-8285.

Ferguson, J. N., Young, L. J., Hearn, E. F., Matzuk, M. M., Insel, T. R., and Winslow, J. T. (2000). Social amnesia in mice lacking the oxytocin gene. Nat. Genet. 25, 284-288.

Fleming, A. S., Kraemer, G. W., Gonzalez, A., Lovic, V., Rees, S., and Melo, A. (2002). Mothering begets mothering: the transmission of behaviour and its neurobiology across generation. Pharmacol. Biochem. Behav. 73, 61-75.

Fleming, A. S., O'Day, D. H., and Kraemer, G. W. (1999). Neurobiology of mother-infant interactions: experience and central nervous system plasticity across development and generations. Neurosci. Biobehav. Rev. $23,673-685$.

Frasch, A., Zetzsche, T., Steiger, A., and Jirikowski, G. F. (1995). Reduction of plasma oxytocin levels in patients suffering from major depression. Adv. Exp. Med. Biol. 395, 257-258.

Gheusi, G., Blunthe, R.-M., Goodall, G., and Dantzer, R. (1994). Social and individual recognition in rodents: methodological aspects and neurobiological bases. Behav. Processes 33, 59-88.

Gil-Bea, F. J., Aisa, B., Schliebs, R., and Ramírez, M. J. (2007). Increase of locomotor activity underlying the behavioral disinhibition in tg2576 mice. Behav. Neurosci. 121, 340-344.

Gimpl, G., and Fahrenholz, F. (2001). The oxytocin receptor system: structure, function, and regulation. Physiol. Rev. 81, 629-683.

Goldman, M., Marlow-O'Connor, M., Torres, I., and Carter, C. S. (2008). Diminished plasma oxytocin in schizophrenic patients with neuroendocrine dysfunction and emotional deficits. Schizophr. Res. 98, 247-255.

Gordon, I., Zagoory-Sharon, O., Leckman, J. F., and Feldman, R. (2010). Oxytocin and the development of parenting in humans. Biol. Psychiatry 68, 377-382.

Guastella, A. J., Einfeld, S. L., Gray, K. M., Rinehart, N. J., Tonge, B. J., Lambert, T. J., et al. (2010). Intranasal oxytocin improves emotion recognition for youth with autism spectrum disorders. Biol. Psychiatry 67, 692-694.

Guastella, A. J., Howard, A. L., Dadds, M. R., Mitchell, P., and Carson, D. S. (2009). A randomized controlled trial of intranasal oxytocin as an adjunct to exposure therapy for social anxiety disorder. Psychoneuroendocrinology 34, 917-923.

Guastella, A. J., and MacLeod, C. (2012). A critical review of the influence of oxytocin nasal spray on social cognition in humans: evidence and future directions. Horm. Behav. 61, 410-418.

Gutkowska, J., Broderick, T. L., Bogdan, D., Wang, D., Lavoie, J. M., and Jankowski, M. (2009). Downregulation of oxytocin and natriuretic peptides in diabetes: possible implications in cardiomyopathy. J. Physiol. 587, 4725-4736.

Heinrichs, M., and Domes, G. (2008). Neuropeptides and social behaviour: effects of oxytocin and vasopressin in humans. Prog. Brain Res. 170, 337-350.

Higashida, H., Lopatina, O., Yoshihara, T., Pichugina, Y. A., Soumarokov, A. A., Munesue, T., et al. (2010). Oxytocin signal and social behaviour: comparison among adult and infant oxytocin, oxytocin receptor and $\mathrm{CD} 38$ gene knockout mice. $J$. Neuroendocrinol. 22, 373-379.

Higashida, H., Yokoyama, S., Huang, J. J., Liu, L., Ma, W. J., Akther, S., et al. (2012a). Social memory, amnesia, and autism: brain oxytocin secretion is regulated by $\mathrm{NAD}(+)$ metabolites and single nucleotide polymorphisms of CD38. Neurochem. Int. 61, 828-838.

Higashida, H., Yokoyama, S., Kikuchi, M., and Munesue, T. (2012b). CD38 and its role in oxytocin secretion and social behavior. Horm. Behav 61,351-358.

Higashida, H., Yokoyama, S., Munesue, T., Kikuchi, M., Minabe, Y., and Lopatina, O. (2011). CD38 gene knockout juvenile mice: a model of oxytocin signal defects in autism. Biol. Pharm. Bull. 34, 1369-1372.

Hirosawa, T., Kikuchi, M., Higashida, H., Okumura, E., Ueno, S., Shitamichi, K., et al. (2012). Oxytocin attenuates feelings of hostility depending on emotional context and individuals' characteristics. Sci. Rep. 2, 384 .

Hoge, E. A., Lawson, E. A., Metcalf, C. A., Keshaviah, A., Zak, P. J., Pollack, M. H., et al. (2012). Plasma oxytocin immunoreactive products and response to trust in patients with social anxiety disorder. Depress. Anxiety 29, 924-930.

Hollander, E., Bartz, J., Chaplin, W. Phillips, A., Sumner, J., Soorya, L., et al. (2007). Oxytocin increases retention of social cognition in autism. Biol. Psychiatry 61, 498-503.

Hollander, E., Novotny, S., Hanratty, M., Yaffe, R., DeCaria, C. M., Aronowitz, B. R., et al. (2003). Oxytocin infusion reduces repetitive behaviors in adults with autistic and Asperger's disorders. Neuropsychopharmacology

28 , 193-198.

Howard, M., Grimaldi, J. C., Bazan, J. F., Lund, F. E., Santos-Argumedo, L., Parkhouse, R. M., et al. (1993). Formation and hydrolysis of cyclic ADP-ribose catalyzed by lymphocyte antigen CD38. Science 262, 1056-1059.

Huffmeijer, R., Alink, L. R., Tops, M., Grewen, K. M., Light, K. C., Bakermans-Kranenburg, M. J., et al. (2012). Salivary levels of oxytocin remain elevated for more than two hours after intranasal oxytocin administration. Neuro Endocrinol. Lett. 33, 21-25.

Hurlemann, R., Patin, A., Onur, O. A., Cohen, M. X., Baumgartner, T., Metzler, S., et al. (2010). Oxytocin enhances amygdala-dependent, socially reinforced learning and emotional empathy in humans. $J$. Neurosci. 30, 4999-5007.

Iijima, M., and Chaki, S. (2005). Separation-induced ultrasonic vocalization in rat pups: further pharmacological characterization. Pharmacol. Biochem. Behav. 82, 652-657.

Insel, T. R. (1997). A neurobiological basis of social attachment. Am. J. Psychiatry 154, 726-735.

Insel, T. R. (2010). The challenge of translation in social neuroscience: a review of oxytocin, vasopressin, and affiliative behavior. Neuron 65 , 768-779.

Insel, T. R., and Young, L. J. (2001). The neurobiology of attachment. Nat. Rev. Neurosci. 2, 129-136.

Ishak, W. W., Kahloon, M., and Fakhry, H. (2011). Oxytocin role in enhancing well-being: a literature review. J. Affect. Disord. 130, 1-9.

Jankowski, M., Gonzalez-Reyes, A., Noiseux, N., and Gutkowska, J. (2012). Oxytocin in the heart regeneration. Recent Pat. Cardiovasc. Drug Discov. 7, 81-87.

Jankowski, M., Hajjar, F., Kawas, S. A., Mukaddam-Daher, S., Hoffman, G. McCann, S. M., et al. (1998). Rat heart: a site of oxytocin production and action. Proc. Natl. Acad. Sci. U.S.A. 95, 14558-14563.

Jin, D., Liu, H. X., Hira, H., Torashima, T., Nagain, T., Lopatina, O., et al. (2007). CD38 is critical for social behaviour by regulating oxytocin secretion. Nature 446, 41-45.

Kavaliers, M., Choleris, E., Agmo, A., Braun, W. J., Colwell, D. D., Muglia, L. J., et al. (2006). Inadvertent social information and the avoidance of parasitized male mice: a role for oxytocin. Proc. Natl. Acad. Sci. U.S.A. 103, 4293-4298.

Kavaliers, M., Choleris, E., and Pfaff, D. W. (2005). Genes, odours and the recognition of parasitized individuals by rodents. Trends Parasitol. 21, 423-429.

Kendrick, K. M. (2000). Oxytocin, motherhood and bonding. Exp. Physiol. 85, 111S-124S.

Kendrick, K. M. (2006). Introduction. The neurobiology of social recognition, attraction and bonding. Philos. Trans. R. Soc. Lond. B Biol. Sci. 361, 2057-2059.

Kendrick, K. M., Da Costa, A. P., Broad, K. D., Ohkura, S., Guevara, R., Levy, F., et al. (1997). Neural control of maternal behaviour and olfactory recognition of offspring. Brain Res. Bull. 44, 383-395.

Kendrick, K. M., and Keverne, E. B. (1992). Control of synthesis and release of oxytocin in the sheep 
brain. Ann. N. Y. Acad. Sci. 652, 102-121.

Kéri, S., Kiss, I., and Kelemen, O. (2009). Sharing secrets: oxytocin and trust in schizophrenia. Soc. Neurosci. 4, 287-293.

Keverne, E. B., and Kendrick, K. M. (1992). Oxytocin facilitation of maternal behavior in sheep. Ann. N. Y. Acad. Sci. 652, 83-101.

Kim, B. J., Park, K. H., Yim, C. Y., Takasaw, S., Okamoto, H., Im, M. J., et al. (2008). Generation of nicotinic acid adenine dinucleotide phosphate and cyclic ADP-ribose by glucagon-like peptide-1 evokes $\mathrm{Ca}^{+}$signal that is essential for insulin secretion in mouse pancreatic islets. Diabetes 57, 868-878.

Kiss, I., Levy-Gigi, E., and Kéri, S. (2011). CD 38 expression, attachment style and habituation of arousal in relation to trust-related oxytocin release. Biol. Psychol. 88, 223-226.

Klin, A., Saulnier, C. A., Sparrow, S. S., Cicchetti, D. V., Volkmar, F. R., and Lord, C. (2007). Social and communication abilities and disabilities in higher functioning individuals with autism spectrum disorders: the Vineland and the ADOS. J. Autism Dev. Disord. 37, 748-759.

Kosaka, H., Munesue, T., Ishitobi, M., Asano, M., Omori, M., Sato, M., et al. (2012). Long-term oxytocin administration improves social behaviors in a girl with autistic disorder. BMC Psychiatry 12:110. doi:10.1186/1471-244X-12-110

Kosfeld, M., Heinrichs, M., Zak, P. J., Fischbacher, U., and Fehr, E. (2005). Oxytocin increases trust in humans. Nature 435, 673-676.

Lambert, R. C., Dayanithi, G., Moos, F. C., and Richard, P. (1994). A rise in the intracellular $\mathrm{Ca}_{2}^{+}$concentration of isolated rat supraoptic cells in response to oxytocin. J. Physiol. 478, 275-287.

Landgraf, R., and Neumann, I. D. (2004). Vasopressin and oxytocin release within the brain: a dynamic concept of multiple and variable modes of neuropeptide communication. Front. Neuroendocrinol. 25, 150-176.

Leckman, J. F., Goodman, W. K., North, W. G., Chappell, P. B., Price, L. H., Pauls, D. L., et al. (1994). The role of central oxytocin in obsessive compulsive disorder and related normal behavior. Psychoneuroendocrinology 19, 723-749.

Lee, H. C. (2012). The cyclic ADPribose/NAADP/CD38-signaling pathway: past and present. Messenger 1, 16-33.
Lee, H. C., and Aarhus, R. (1995). A derivative of NADP mobilizes calcium stores insensitive to inositol trisphosphate and cyclic ADP-ribose. J. Biol. Chem. 270, 2152-2157.

Lerer, E., Levi, S., Israel, S., Yaari, M., Nemanov, L., Mankuta, D., et al. (2010). Low CD38 expression in lymphoblastoid cells and haplotypes are both associated with autism in a family-based study. Autism Res. 3, 293-302.

Lerer, E., Yirmiya, R., Salomon, S., and Ebstein, R. P. (2009). Polymorphisms in the CD38 gene are associated with socialization skills in autism spectrum disorders and correlate with expression levels. Isr. J. Psychiatry 46, 41 (S6 2.5).

Lim, M. M., and Young, L. J. (2006). Neuropeptidergic regulation of affiliative behavior and social bonding in animals. Horm. Behav. 50, 506-517.

Liu, H. X., Lopatina, O., Amina, S. Higashida, C., Islam, M. S., Graeff, R., et al. (2012a). Intracellular calcium concentrations regulated by cyclic ADP-ribose and heat in the mouse hypothalamus. Messenger 1, 150-159.

Liu, H. X., Lopatina, O., Higashida, C., Fujimoto, H., Akther, S., Inzhutova, A., et al. (2012b). Displays of mouse pup retrieval as a paternal parental behaviour following communicative interaction with the maternal mate. Nature Commun. doi:10.1038/ncomms2336

Liu, H. X., Lopatina, O., Higashida, C., Tsuji, T., Kato, I., Takasawa, S., et al. (2008). Locomotor activity, ultrasonic vocalization and oxytocin levels in infant CD38 knockout mice. Neurosci. Lett. 448, 67-70.

Lopatina, O., Inzhutova, A., Pichugina, Y. A., Okamoto, H., Salmina, A. B., and Higashida, H. (2011). Reproductive experience affects parental retrieval behaviour associated with increased plasma oxytocin levels in wild-type and Cd38-knockout mice. J. Neuroendocrinol. 23, 1125-1133.

Lopatina, O., Liu, H. X., Amina, S., Hashii, M., and Higashida, $\mathrm{H}$. (2010). Oxytocin-induced elevation of ADP-ribosyl cyclase activity, cyclic ADP-ribose or $\mathrm{Ca}^{2+}$ concentrations is involved in autoregulation of oxytocin secretion in the hypothalamus and posterior pituitary in male mice. Neuropharmacology 58, 50-55.

Macbeth, A. H., Lee, H. J., Edds, J., and Young, W. S. III (2009). Oxytocin and the oxytocin receptor underlie intrastrain, but not interstrain, social recognition. Genes Brain Behav. 8 558-567.

MacDonald, E., Dadds, M. R., Brennan, J. L., Williams, K., Levy, F., and Cauchi, A. J. (2011). A review of safety, side-effects and subjective reactions to intranasal oxytocin in human research. Psychoneuroendocrinology 36, 1114-1126.

MacDonald, K., and MacDonald, T. M. (2010). The peptide that binds: a systematic review of oxytocin and its prosocial effects in humans. Harv. Rev. Psychiatry 18, 1-21.

Magni, G., Amici, A., Emanuelli, M., Orsomando, G., Raffaelli, N., and Ruggieri, S. (2004). Enzymology of $\mathrm{NAD}^{+}$homeostasis in man. Cell. Mol. Life Sci. 61, 19-34.

Malavasi, F., Deaglio, S., Funaro, A., Ferrero, E., Horenstein, A. L., Ortolan, E., et al. (2008). Evolution and function of the ADP ribosyl cyclase/CD38 gene family in physiology and pathology. Physiol. Rev. 88, 841-886.

Mantella, R. C., Vollmer, R. R., Li, X. and Amico, J. A. (2003). Female oxytocin-deficient mice display enhanced anxiety-related behavior. Endocrinology 144, 2291-2296.

Marazziti, D., and Cassano, G. B. (2003). The neurobiology of attraction. $J$. Endocrinol. Invest. 26, 58-60.

Marazziti, D., Dell'Osso, B., Baroni, S., Mungai, F., Catena, M., Rucci, P., et al. (2009). A relationship between oxytocin and anxiety of romantic attachment. Clin. Pract. Epidemiol. Ment. Health 28, 1-6.

Marroni, S. S., Nakano, F. N., Gati, C. D. Oliveira, J. A., Antunes-Rodrigues, J., and Garcia-Cairasco, N. (2007). Neuroanatomical and cellular substrates of hypergrooming induced by microinjection of oxytocin in central nucleus of amygdala, an experimental model of compulsive behavior. Mol. Psychiatry 12, 1103-1117.

Matthiesen, A. S., Ransjo-Arvidson, A. B., Nissen, E., and Uvnas-Moberg, K. (2001). Postpartum maternal oxytocin release by newborns: effects of infant hand massage and sucking. Birth 28, 13-19.

McCarthy, M. M., McDonald, C. H., Brooks, P. J., and Goldman, D. (1996). An anxiolytic action of oxytocin is enhanced by estrogen in the mouse. Physiol. Behav. 60, 1209-1215.

McEwen, B. B. (2004). Brain-fluid barriers: relevance for theoretical controversies regarding vasopressin and oxytocin memory research. $A d v$. Pharmacol. 50, 531-592, 655-708.

Meaney, M. J. (2001). Maternal care, gene expression, and the transmission of individual differences in stress reactivity across generation. Annu. Rev. Neurosci. 24, 1161-1192.

Meinlschmidt, G., and Heim, C. (2008). The role of oxytocin in neuropsychiatric disorders. Curr. Med. Chem. 15, 698-704.

Meyer-Lindenberg, A., Domes, G., Kirsch, P., and Heinrichs, M. (2011). Oxytocin and vasopressin in the human brain: social neuropeptides for translational medicine. Nat. Rev. Neurosci. 12, 524-538.

Mizuguchi, M., Otsuka, N., Sato, M., Ishii, Y., Kon, S., Yamada, M., et al. (1995). Neuronal localization of CD38 antigen in the human brain. Brain Res. 697, 235-240.

Modahl, C., Green, L., Fein, D., Morris, M., Waterhouse, L., Feinstein, C., et al. (1998). Plasma oxytocin levels in autistic children. Biol. Psychiatry 43, 270-277.

Modi, M. E., and Young, L. J. (2012). The oxytocin system in drug discovery for autism: animal models and novel therapeutic strategies. Horm. Behav. 61, 340-350.

Modney, B. K., and Hatton, G. I. (1994). Maternal behaviours: evidence that they feed back to alter brain morphology and function. Acta Paediatr. Suppl. 397, 29-32.

Moos, F., Freund-Mercier, M. J., Guerner, Y., Guerner, J. M., Stoeckel, M. E., and Richard, P. (1984). Release of oxytocin and vasopressin by magnocellular nuclei in vitro: specific facilitatory effect of oxytocin on its own release. J. Endocrinol. 102, 63-72.

Moy, S. S., Nadler, J. J., Poe, M. D., Nonneman, R. J., Young, N. B., Koller, B. H., et al. (2008). Development of a mouse test for repetitive, restricted behaviors: relevance to autism. Behav. Brain Res. 188, 178-194.

Moy, S. S., Nadler, J. J., Young, N. B., Perez, A., Holloway, L. P., Barbaro, R. P., et al. (2007). Mouse behavioral tasks relevant to autism: phenotypes of 10 inbred strains. Behav. Brain Res. 176, 4-20.

Munesue, T., Yokoyama, S., Nakamura, K., Anitha, A., Yamada, K., Hayashi, K., et al. (2010). Two genetic variants of CD38 in subjects with autism spectrum disorder and controls. Neurosci. Res. 67, 181-191.

Naber, F., van Ijzendoorn, M. H., Deschamps, P., van Engeland, H., and Bakermans-Kranenburg, M. J. (2010). Intranasal oxytocin increases fathers' observed responsiveness during play with their children: a 
double-blind within-subject experiment. Psychoneuroendocrinology 35, 1583-1586.

Nagasawa, M., Okabe, S., Mogi, K., and Kikusui, T. (2012). Oxytocin and mutual communication in mother-infant bonding. Front. Hum. Neurosci. 6:31. doi:10.3389/fnhum.2012.00031

Nelson, E. E., and Panksepp, J. (1998). Brain substrates of infant mother attachment: contributions of opioids, oxytocin and norepinephrine. Neurosci. Biobehav. Rev. 22, 437-452.

Neumann, I., Douglas, A. J., Pittman, Q. J., Russell, J. A., and Landgraf, R. (1996). Oxytocin released within the supraoptic nucleus of the rat brain by positive feedback action is involved in parturitionrelated events. J. Neuroendocrinol. 8 , 227-233.

Neumann, I., Koehler, E., Landgraf, R., and Summy-Long, J. (1994). An oxytocin receptor antagonist infused into the supraoptic nucleus attenuates intranuclear and peripheral release of oxytocin during suckling in conscious rats. Endocrinology 134, 141-148.

Neumann, I. D. (2008). Brain oxytocin: a key regulator of emotional and social behaviours in both females and males. J. Neuroendocrinol. 20, 858-865.

Nishimori, K., Young, L. J., Guo, Q., Wang, Z., Insel, T. R., and Matzuk, M. M. (1996). Oxytocin is required for nursing but is not essential for parturition or reproductive behavior. Proc. Natl. Acad. Sci. U.S.A. 93, 11699-11704.

Okabe, S., Nagasawa, M., Kihara, T., Kato, M., Harada, T., Koshida, N., et al. (2010). The effects of social experience and gonadal hormones on retrieving behavior of mice and their responses to pup ultrasonic vocalizations. Zool. Sci. 27, 790-795.

Oliver, G., and Schäfer, E. A. (1895). On the physiological action of extracts of pituitary body and certain other glandular organs: preliminary communication. J. Physiol. 18, 277-279.

Onaivi, E. S., Benno, R., Halpern, T., Mehanovic, M., Schanz, N., Sanders, C., et al. (2011). Consequences of cannabinoid and monoaminergic system disruption in a mouse model of autism spectrum disorders. Curr. Neuropharmacol. 9, 209-214.

Parker, K. J., Kinney, L. F., Phillips, K. M., and Lee, T. M. (2001). Paternal behavior is associated with central neurohormone receptor binding patterns in meadow voles (Microtus pennsylvanicus). Behav. Neurosci. 115, 1341-1348.

Pawluski, J. L., Walker, S. K., and Galea, L. A. (2006). Reproductive experience differentially affects spatial reference and working memory performance in the mother. Horm. Behav. 49, 143-149.

Pedersen, C. A. (1999). "Oxytocin control of maternal behavior: regulation of sex steroids and offspring stimuli," in The Integrative Neurobiology of Affiliation, eds S. C. Carter, I. Lederhendler, and B. Kirkpatrick (Cambridge, MA: MIT Press), 301-320.

Pedersen, C. A., and Boccia, M. L. (2002). Oxytocin maintains as well as initiates female sexual behavior: effects of a highly selective oxytocin antagonist. Horm. Behav. 41, 170-177.

Pedersen, C. A., and Boccia, M. L. (2003). Oxytocin antagonism alters rat dams' oral grooming and upright posturing over pups. Physiol. Behav. 80, 233-241.

Pedersen, C. A., and Boccia, M. L. (2006). Vasopressin interactions with oxytocin in the control of female sexual behavior. Neuroscience 139, 843-851.

Petersson, M., and Uvnäs-Moberg, K. (2008). Postnatal oxytocin treatment of spontaneously hypertensive male rats decreases blood pressure and body weight in adulthood. Neurosci. Lett. 440, 166-169.

Pierrehumbert, B., Torrisi, R., Laufer, D., Halfon, O., Ansermet, F., and Beck Popovic, M. (2010). Oxytocin response to an experimental psychosocial challenge in adults exposed to traumatic experiences during childhood or adolescence. Neuroscience 166, 168-177.

Popik, P., Vetulani, J., and van Ree, J. M. (1992). Low doses of oxytocin facilitate social recognition in rats. Psychopharmacology (Berl.) 106, 71-74.

Richard, P., Moos, F., Freund-Mercier, M. J. (1991). Central effects of oxytocin. Physiol. Rev. 71, 331-370.

Riebold, M., Mankuta, D., Lerer, E., Israel, S., Zhong, S., Nemanov, L., et al. (2011). All-trans retinoic acid upregulates reduced $\mathrm{CD} 38$ transcription in lymphoblastoid cell lines from autism spectrum disorder. Mol. Med. 17, 799-806.

Riem, M. M., Bakermans-Kranenburg, M. J., Pieper, S., Tops, M., Boksem, M. A., Vermeiren, R. R., et al. (2011). Oxytocin modulates amygdala, insula, and inferior frontal gyrus responses to infant crying: a randomized controlled trial. Biol. Psychiatry 70, 291-297.

Sala, M., Braida, D., Lentini, D., Busnelli, M., Bulgheron, E., Capurro, V., et al. (2011). Pharmacologic rescue of impaired cognitive flexibility, social deficits, increased aggression, and seizure susceptibility in oxytocin receptor null mice. A neurobehavioral model of autism. Biol. Psychia$\operatorname{try} 69,875-882$.

Salmina, A. B., Lopatina, O., Ekimova, M. V., Mikhutkina, S., and Higashida, H. (2010). CD38/cyclic ADP-ribose system: a new player for oxytocin secretion and regulation of social behaviour. J. Neuroendocrinol. 22, 380-392.

Scattoni, M. L., McFarlane, H. G., Zhodzishsky, V., Caldwell, H. K. Young, W. S., Ricceri, L., et al. (2008). Reduced ultrasonic vocalizations in vasopressin $1 \mathrm{~b}$ knockout mice. Behav. Brain Res. 187, 371-378.

Shu, W., Cho, J. Y., Jiang, Y., Zhang, M., Weisz, D., Elder, G. A., et al. (2005). Altered ultrasonic vocalization in mice with a disruption in the Foxp2 gene. Proc. Natl. Acad. Sci. U.S.A. 102, 9643-9648.

Silverman, J. L., Turner, S. M., Barkan, C. L., Tolu, S. S., Saxena, R., Hung, A. Y., et al. (2011). Sociability and motor functions in Shank1 mutant mice. Brain Res. 1380, 120-137.

Strathearn, L., Fonagy, P., Amico, J., and Montague, P. R. (2009). Adult attachment predicts maternal brain and oxytocin response to infant cues. Neuropsychopharmacology 34, 2655-2666.

Strathearn, L., Iyengar, U., Fonagy, P., and Kim, S. (2012). Maternal oxytocin response during motherinfant interaction: associations with adult temperament. Horm. Behav. 61, 429-435.

Striepens, N., Kendrick, K. M., Maier, W., and Hurlemann, R. (2011). Prosocial effects of oxytocin and clinical evidence for its therapeutic potential. Front. Neuroendocrinol. $32,426-450$.

Takasawa, S., Akiyama, T., Nata, K. Kuroki, M., Tohgo, A., Noguchi, N., et al. (1998). Cyclic ADP-ribose and inositol 1,4,5-trisphosphate as alternate second messengers for intracellular $\mathrm{Ca}^{2+}$ mobilization in normal and diabetic beta-cells. J. Biol. Chem. 273, 2497-2500

Takayanagi, Y., Yoshida, M., Bielsky, I. F., Ross, H. E., Kawamata, M., Onaka, T., et al. (2005). Pervasive social deficits, but normal parturition, in oxytocin receptor-deficient mice. Proc. Natl. Acad. Sci. U.S.A. 102, 16096-16101.

Tamma, R., Colaianni, G., Zhu, L., DiBenedetto, A., Greco, G., Montemurro, G., et al. (2009). Oxytocin is an anabolic bone hormone. Proc. Natl. Acad. Sci. U.S.A. 106, 7149-7154.

Tang-Martinez, Z. (2003). Emerging themes and future challenges: forgotten rodent, neglected questions. J. Mammal. 84, 1212-1227.

Thackare, H., Nicholson, H. D., and Whittington, K. (2006). Oxytocin - its role in male reproduction and new potential therapeutic uses. Hum. Reprod. Update 12, 437-448.

Tobin, V. A., Douglas, A. J., Leng, G., and Ludwig, M. (2011). The involvement of voltage-operated calcium channels in somato-dendritic oxytocin release. PLoS ONE 6:e25366. doi:10.1371/journal.pone.0025366

Tomizawa, K., Iga, N., Lu, Y. F., Moriwaki, A., Matsushita, M., Li, S. T., et al. (2003). Oxytocin improves long-lasting spatial memory during motherhood through MAP kinase cascade. Nat. Neurosci. 6, 384-390.

Tops, M., Van Peer, J. M., Korf, J., Wijers, A. A., and Tucker, D. M. (2007). Anxiety, cortisol, and attachment predict plasma oxytocin. Psychophysiology $44,444-449$.

Touma, C., Bunck, M., Glasl, L., Nussbaumer, M., Palme, R., Stein, H., et al. (2008). Mice selected for high versus low stress reactivity: a new animal model for affective disorders. Psychoneuroendocrinology 33, 839-862.

Uckert, S., Becker, A. J., Ness, B. O., Stief, C. G., Scheller, F., Knapp, W. H., et al. (2003). Oxytocin plasma levels in the systemic and cavernous blood of healthy males during different penile conditions. World J. Urol. 20, 323-326.

Vignozzi, L., Filippi, S., Luconi, M., Morelli, A., Mancina, R., Marini, M., et al. (2004). Oxytocin receptor is expressed in the penis and mediates an estrogen-dependent smooth muscle contractility. Endocrinology 145, 1823-1834.

Wang, Z., and Aragona, B. J. (2004). Neurochemical regulation of pair bonding in male prairie voles. Physiol. Behav. 83, 319-328.

Weisman, O., Zagoory-Sharon, O., and Feldman, R. (2012). Oxytocin administration to parent enhances infant physiological and behavioral readiness for social 
engagement. Biol. Psychiatry 72, 982-989.

Winslow, J. T., Hearn, E. F., Ferguson, J., Young, L. J., Matzuk, M. M., and Insel, T. R. (2000). Infant vocalization, adult aggression, and fear behavior of an oxytocin null mutant mouse. Horm. Behav. 37, 145-155.

Wöhr, M., Roullet, F. I., and Crawley, J. N. (2011). Reduced scent marking and ultrasonic vocalizations in the BTBR $\mathrm{T}+\mathrm{tf} / \mathrm{J}$ mouse model of autism. Genes Brain Behav. 10, 35-43.

Won, H., Mah, W., Kim, E., Kim, J. W., Hahm, E. K., Kim, M. H., et al. (2011). GIT1 is associated with ADHD in humans and ADHD-like behaviors in mice. Nat. Med. 17, 566-572.

Yamasue, H., Kuwabara, H., Kawakubo, Y., and Kasai, K. (2009). Oxytocin, sexually dimorphic features of the social brain, and autism. Psychiatry Clin. Neurosci. 63, 129-140.

Yang, J. (1994). Intrathecal administration of oxytocin induces analgesia in low back pain involving the endogenous opiate peptide system. Spine 19, 867-871.

Young, L. J., Lim, M. M., Gingrich, B., and Insel, T. R. (2001). Cellular mechanisms of social attachment. Horm. Behav. 40, 133-138.

Young, L. J., and Wang, Z. (2004). The neurobiology of pair bonding. Nat. Neurosci. 7, 1048-1054.

Zak, P. J., Stanton, A. A., and Ahmadi, S. (2007). Oxytocin increases generosity in humans. PLoS ONE 2:e1128. doi:10.1371/journal.pone. 0001128

Conflict of Interest Statement: The authors declare that the research was conducted in the absence of any commercial or financial relationships that could be construed as a potential conflict of interest.

Received: 13 September 2012; accepted: 01 December 2012; published online: 11 January 2013.
Citation: Lopatina O, Inzhutova A, Salmina $A B$ and Higashida $H$ (2013) The roles of oxytocin and CD38 in social or parental behaviors. Front. Neurosci. 6:182. doi: 10.3389/fnins.2012.00182 This article was submitted to Frontiers in Neuroendocrine Science, a specialty of Frontiers in Neuroscience.

Copyright (c) 2013 Lopatina, Inzhutova, Salmina and Higashida. This is an openaccess article distributed under the terms of the Creative Commons Attribution License, which permits use, distribution and reproduction in other forums, provided the original authors and source are credited and subject to any copyright notices concerning any third-party graphics etc. 